\title{
ERRATUM
}

\section{A. W. Sáenz \\ Erratum to: Determination of stresses from their stress trajectories in plane elastic systems: the five constant theorem}

Published online: 15 August 2010

(C) Springer-Verlag 2010

\section{Erratum to: Acta Mech 208, 215-225 (2009) \\ DOI 10.1007/s00707-008-0118-3}

Unfortunately, several errors need to be rectified in the original version of the article that is published. The corrections and the correct version are mentioned below:

1. Page 217, first paragraph, third line: " $\tau_{x x}=\tau_{x y}=0$ " should read " $\tau_{x x}=\tau_{y y}$ and $\tau_{x y}=0$ ".

2. Page 219, sixth paragraph, first line: in the second identity therein, “ $\frac{\partial^{2}}{\partial} \zeta$ " should read " $\frac{\partial^{2}}{\partial \zeta^{2}}$ ".

3. Page 220: The second line of Theorem 2 should read "of two independent complex variables $\zeta, \zeta$ ' for $|\zeta|,\left|\zeta^{\prime}\right|<\rho$, which is given by".

4. Page 221: The third line after Eq. (25.4), "at each point $\left(\zeta, \zeta^{\prime}\right) \in \sum$ " should read "for $|\zeta|,\left|\zeta^{\prime}\right|<\rho$ ".

5. Page 222: In the first line after Theorem 3. "The sent lemma" should read "Lemma 5".

6. Italicize the following: " $\mathrm{T}$ " in the second line of the first paragraph of Sec. 3, page 220: "f,g,H" in the second line after Eq. (25.4) page 221; and " $\mathrm{f}^{\prime}(0)$ " in Eqs. (42.3) and (43), page 224.

7. The following corrections concern the references listed on page 225:

(a) In Ref. [2], "Strömlinien" should read "Stromlinien" and "U." should read "u.".

(b) In Ref. [5], "Inter-Balkan." should read "Interbalkan.".

(c) In Refs. [8-11], "Mukhademiev" should read "Mukhamediev".

(d) In Ref. [14], "Elastizitäts-Theorie" should read "Elastizitätstheorie," and "Z.F. Math. U. Phys." should read "Z. f. Math. u. Phys.".

(e) In Ref. [17], "a" and "aus" should read "à" and "aux," respectively.

The online version of the original article can be found under doi:10.1007/s00707-008-0118-3.

A. W. Sáenz

Physics Department, Catholic University of America, Washington, DC 20064, USA

A. W. Sáenz $(\bowtie)$

Naval Research Laboratory, Washington, DC 20375, USA

E-mail: saenz@dave.nrl.navy.mil 